\title{
Evaluation of North Carolina child care safety regulations
}

\author{
J B Kotch, J M Hussey, A Carter
}

See end of article for authors' affiliations

\section{Correspondence to:} Dr Jonathan Kotch, Department of Maternal and Child Health, CB\# 7445, Rosenau Hall, University of North Carolina, Chapel Hill, NC 27599-7445, USA jonathan_kotch@unc.edu

\begin{abstract}
Introduction: The goal of this study was to track any changes in injuries and injury hazards during the first 3.5 years of implementation of the North Carolina Child Care Commission's 1996 playground safety regulations.

Methods: All reports $(n=5402)$ of medically attended injuries in regulated child care settings in North Carolina during the period 1 January 1997 through 30 June 2000 were reviewed and analyzed. A total of 294 playground safety inspections were conducted in November and December 1998 in randomly selected North Carolina child care centers, and the playground safety inspections were repeated in 76 child care centers in August 2000. Finally, in 1999 a 1992 child care center director self assessment of safety features in classrooms was sent to the directors of 291 of the 294 centers.

Results: The annual rate of reported, medically attended injuries occurring in regulated child care facilities in North Carolina declined by 22\% from 1997 to 1999. The playground safety inspections in the year 2000 revealed that, for nine of 10 playground concerns and 12 of 18 playground safety hazards, average ratings were equal to or better than those of 1998. Finally, the director surveys revealed no dramatic changes in classroom safety hazards since 1992.

Discussion: This study represents the first time that the authors are aware of that a significant decline in state-wide child care injury rates has been associated with improved regulation of playground safety in the US.
\end{abstract}

W th changes in female labor force participation, household composition, and the demand for early childhood education, the proportion of US children in non-relative, out-of-home child care arrangements has grown rapidly over the past several decades. ${ }^{1}$ The growth in the proportion of children in center based care has been especially dramatic. Among preschoolers with employed mothers, the percentage in center based care increased from 6\% in 1965 to $32 \%$ in $1997 .{ }^{12}$ Currently, among US children with employed mothers, approximately $48 \%$ of children under 5 and approximately $31 \%$ of children in kindergarten through third grade receive non-relative child care (either in a family child care home or in a center based program). ${ }^{2}{ }^{3}$

As the proportion of children in regulated child care arrangements has increased so too has concern about the safety of these settings. The best estimates of serious (that is, medically attended) injury rates in child care settings range from 1.5 to 3.2 injuries per 100000 child hours of exposure. ${ }^{4-8}$ Assuming that full time attendance is equivalent to 2000 hours of injury exposure per child per year (that is, 40 hours/ week $\times 50$ weeks per year), this means that approximately one medically attended injury per year occurs for every 16 to 33 full time equivalent children enrolled in child care.

All existing evidence suggests that children are as safe, on average, while in child care settings as they are while being cared for in their homes. A survey of 656 families in central North Carolina found that while the rate of minor injuries to children under 5 was significantly higher in center based care, there were no significant differences in medically attended injury rates among center based care, home care, and other out-of-home care. ${ }^{9}$ Similarly, a study of 2204 children under 5 who belonged to a large health maintenance organization in Washington State found no statistically significant difference, after adjusting for exposure, between the risk of sustaining a medically attended injury while under the supervision of child care personnel and the risk of injury while being cared for in their own home or the home of a babysitter. ${ }^{7}$ A national tele- phone survey of households with children under 5 years of age found that the rate of medically attended injuries in preschoolers was lower in out-of-home care settings ( 1.69 per 100000 child hours) than in home based care (2.66 per 100000 child hours). ${ }^{10}$

The public health impact of child care injuries is further illuminated by data from the National Hospital Ambulatory Medical Care Survey. While not adjusted for exposure (which is typically higher in the home), these data indicate that child care injuries account for a small fraction of all injury related emergency department visits among preschool children. During the 1993-94 period, child care injuries accounted for approximately $3 \%$ of all injury related emergency department visits among US children under age 6 . By comparison, street or highway injuries accounted for $6 \%$ of the total emergency department visits and injuries at home accounted for $62 \%$ of the total. ${ }^{11}$ (Note: place of injury was unspecified for $22 \%$ of all visits.)

In North Carolina, enrollment in child care centers and child care homes has increased nearly 6\% since 1997 alone. Currently, more than 213000 North Carolina children attend out-of-home child care. More than 196000 children are served by the 4000 licensed child care centers in North Carolina, and nearly 17000 children attend one of the 5709 licensed child care homes in the state*. As the number of children in regulated child care arrangements has increased, so has the attention paid to child care injury. In 1995, several serious injuries, including one death, on North Carolina child care center playgrounds heightened concerns in this state and attracted the attention of the state legislature. In the ensuing period, a number of rules addressing the safety of child care

Abbreviations: DCD, Division of Child Development; UNC-CH, University of North Carolina at Chapel Hill

*Enrollment data as of 30 September 2001. 
Table 1 North Carolina's playground rules timetable

\begin{tabular}{|c|c|}
\hline May 1995 & $\begin{array}{l}\text { - Several serious injuries occur on North Carolina child care center playgrounds, including one death } \\
\text { - Rules are very vague- "safe environment" } \\
\text { - Rule making process initiated }\end{array}$ \\
\hline 1 January 1996 & $\begin{array}{l}\text { - Playground rules adopted by the North Carolina Child Care Commission effective } 1 \text { January } 1996 \\
\text { - Date to comply is } 1 \text { January } 1999 \\
\text { - Included is the requirement to submit Incident Reports when a child is injured and receives medical treatment }\end{array}$ \\
\hline 1996-97 & $\begin{array}{l}\text { - North Carolina Child Care Commission receives public comments and concerns about requiring conformance to } \\
\text { Consumer Product Safety Commission (CPSC) guidelines }\end{array}$ \\
\hline 1 June 1997 & $\begin{array}{l}\text { - Contract established with School of Public Health, University of North Carolina at Chapel Hill, to assess changes in } \\
\text { injury data during a three year period following adoption of the safety regulations }\end{array}$ \\
\hline September 1997 & - Requirement that playground equipment conform to CPSC guidelines is repealed by legislation \\
\hline 1 October 1997 & $\begin{array}{l}\text { - North Carolina Child Care Commission adopts temporary rules for playground equipment and surfacing } \\
\text { - New programs or equipment must comply immediately } \\
\text { - Programs currently operating have until } 1 \text { January } 2000 \text { to comply }\end{array}$ \\
\hline February 1998 & $\begin{array}{l}\text { - North Carolina Child Care Commission adopts playground rules with changes from the } 1996 \text { and } 1997 \text { rules } \\
\text { - Rules simplified } \\
\text { - Requires adherence to major safety areas - protrusions, entrapments, fall zones, guard rails, surfacing } \\
\text { - No requirement to meet CPSC guidelines } \\
\text { - Date to comply is extended to } 1 \text { January } 2001 \text { with an additional year given for financial hardship cases } \\
\text { - Effective date of rule changes is } 29 \text { October } 1998\end{array}$ \\
\hline 1 January 2001 & - All child care center playgrounds were to be in compliance with playground rules \\
\hline
\end{tabular}

centers, and homes have been developed and new regulations have been adopted (see table 1). The impact of these new rules on the safety of children is unknown. The purpose of this study therefore is to enumerate and describe medically attended injuries taking place in North Carolina's licensed child care centers and child care homes and to examine indoor and outdoor safety hazards in order to determine if there is a relationship among the implementation of North Carolina's playground safety rules, safety hazards, and trends in the risk of medically attended child care injury.

\section{METHODS}

\section{Medically attended injury rates}

This is a case series study, looking at children 12 years of age and younger experiencing medically attended injuries at regulated child care centers and child care homes in North Carolina. The North Carolina Department of Health and Human Services, Division of Child Development (DCD), provided data from all medically attended injury incident reports filed by child care centers and child care homes in North Carolina for the period I January 1997 through 30 June 2000. According to North Carolina law, any time a child receives medical treatment as a result of an incident occurring at a child care center or child care home, the facility must file an incident report with their child care consultant within seven calendar days. Information about the injury, including time and date of occurrence, location, type of injury, proximate cause, and treatment location is recorded on the one page incident report form. Confidentiality of all injury data provided by child care centers and child care homes was assured.

Completed incident report forms were collected by child care consultants employed by the state and then submitted to the DCD, where they were entered into a FoxPro computer database by DCD staff. These database files (with the child's name omitted) were periodically forwarded to the research staff at the University of North Carolina at Chapel Hill (UNC$\mathrm{CH})$, where they were converted to SPSS files before analysis.

Of the 5402 total incident reports filed during this 3.5 year period, $90.5 \%$ came from child care centers, $3.5 \%$ came from child care homes, and $6.0 \%$ came from an unknown type of child care setting. Because child care centers account for the majority of all injury reports, we focus on injuries in this type of setting.

The DCD also provided research staff with state-wide monthly enrollment counts for child care centers and family child care homes. These enrollment counts were used to estimate monthly, seasonal, and annual injury rates. (The computing formula for the annual rate is provided in the appendix ${ }^{* *}$.) It is important to note that the average monthly enrollment count is a crude indicator of exposure to injury risk. The enrollment counts do not provide any information about the number of hours that children actually spend in child care-a superior indicator of exposure to injury risk. The injury rate estimates in this report assume that each child faces the same level of exposure to injury risk. Further, this report assumes that the average level of exposure per child has remained constant over the 3.5 year study period.

\section{Playground safety audit form}

Playground safety ratings were recorded on the playground safety audit form. ${ }^{12}$ This 14 page form includes rating scales for general playground concerns (for example, disabled access, fencing) and specific types of equipment (slides, swings, etc). For each type of equipment, ratings are collected on such features as sharp points and edges, equipment anchoring, and surfacing. Depending on what equipment it has, a playground may receive up to 108 separate ratings. Each playground feature is rated "poor", "fair", or "good".

The sampling strategy was dictated by the data collection procedure. A list of all 3410 North Carolina child care centers was obtained from the DCD. The state employed child care regulatory consultant responsible for each center was identified on this list. All had been trained in playground safety inspection by the National Playground Safety Institute or by a certified playground safety inspector. Within each consultant's

\footnotetext{
** No summary report of enrollment was prepared for June of 1998, so center enrollment for that month was estimated by averaging the enrollment counts for May and July of 1998.
} 


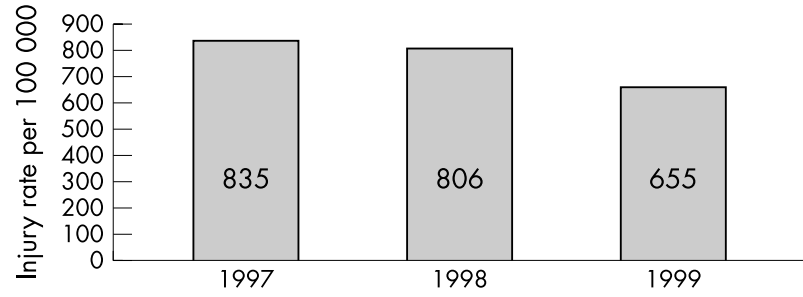

Figure 1 Annual injury rate, North Carolina child care centers, 1997-99.

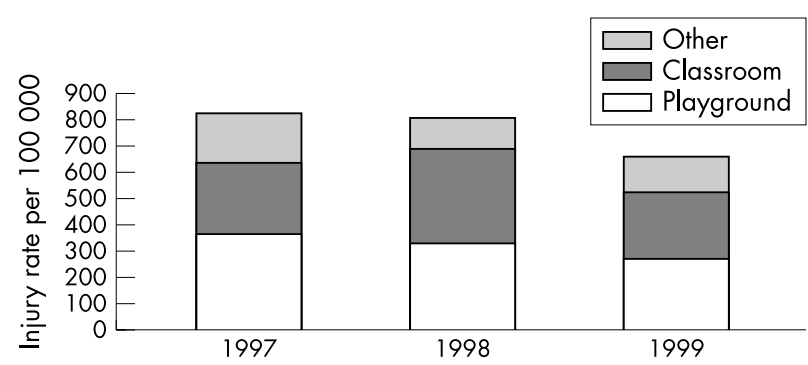

Figure 2 Injury rate by location of injury, North Carolina child care centers, 1997-99.

region, seven centers were randomly selected for auditing. Audits were completed on 294 of the 371 sampled centers, for a completion rate of $79 \%$. The audits were conducted in November and December of 1998.

In August 2000, 10 certified playground inspectors hired with contract funds evaluated a convenience sample of 91 North Carolina child care center playgrounds. Of the 91 centers included in the 2000 audits, 76 had been included in the
1998 audit. Compared with centers not revisited in 2000, this subsample of 76 centers were significantly more likely to be located in urban areas $(76 \% v 62 \%)$. Revisited centers were not significantly different from other centers with respect to the maximum age of intended users, mean and median number of children enrolled, and playground concerns ratings. The mean rating for one of 18 playground features-inappropriate use of pea gravel-was significantly higher (that is, more favorable) among revisited centers.

\section{Child care center director survey}

A four page self administered questionnaire, consisting mainly of check-box and brief write-in questions, was developed to assess indoor safety features and staff safety knowledge in child care centers. The survey includes questions about the serving of potential choking foods to young children; storage of poisonous materials; steps taken to minimize the risk of electric shock, fire, and burns; staff training in cardiopulmonary resuscitation and first aid; emergency procedures; staffing levels; center license type; and the director's educational background. This questionnaire was patterned after and greatly overlaps with a previous mail survey administered to a sample of North Carolina child care center directors in 1992. ${ }^{13}$

Two hundred ninety one North Carolina child care centers whose playgrounds were inspected in November and December, 1998, were mailed a four page survey during the period 8-10 September 1999. The cover letter indicated that the survey was voluntary and confidential. A stamped, preaddressed envelope was included for returning the completed survey. A reminder letter and second copy of the survey was sent to 165 centers in late October/early November, 1999. The survey was reviewed and approved by the UNC-CH School of Public Health Institutional Review Board on research involving

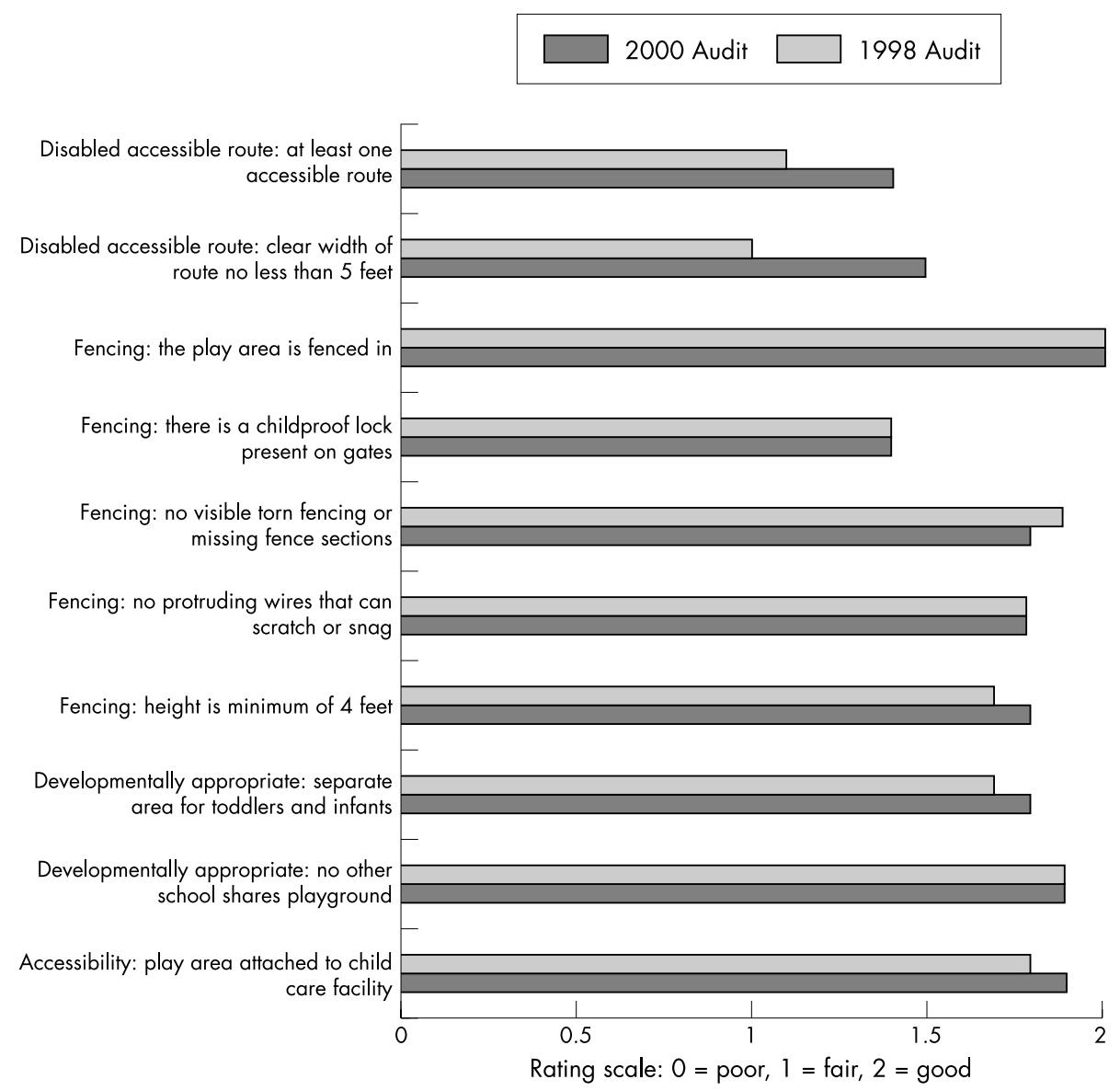

Figure 3 Average safety ratings: playground concerns, North Carolina, 1998 v 2000. 


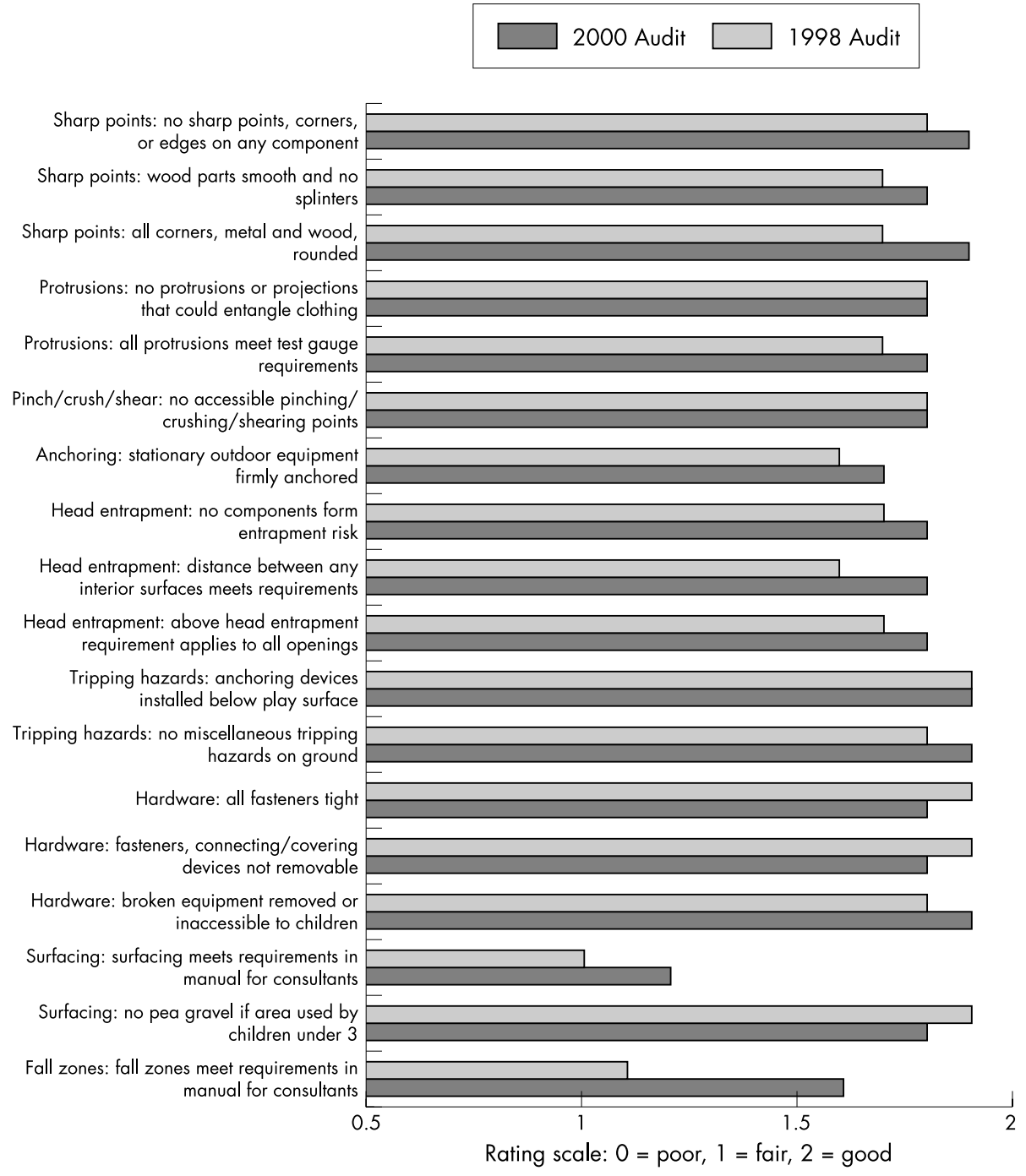

Figure 4 Average safety ratings: playground features, North Carolina, 1998 v 2000.

human subjects. Respondents were not compensated for completing the voluntary survey, which took an estimated 15-20 minutes to complete.

Survey data were keyed in by staff at the Survey Research Unit, UNC-CH. To verify the accuracy of the data entry process, a random $10 \%$ of all surveys were rekeyed. No data entry errors were found.

\section{RESULTS}

\section{Trends in medically attended injury rates}

The annual rate of medically attended injuries in North Carolina child care centers declined 22\% between 1997 and 1999 (the last year for which we have complete data). Most of this decrease took place between 1998 and 1999, when the annual rate of medically attended injuries dropped $19 \%$, from 806 to 655 per 100000 enrollees (fig 1). Playground injuries specifically showed a consistent rate of decline, from 364 per 100000 in 1997 to 336 per 100000 in 1998 and 271 per 100000 in 1999 (fig 2). In 1997, there was one medically attended injury per year for every 120 children enrolled. In 1999, there was one medically attended injury per year for every 153 children enrolled.

An analysis of monthly injury rates over the entire 3.5 year study period confirms that there has been a significant decline in the rate of injuries in North Carolina child care centers. A linear regression analysis revealed a statistically significant $(\mathrm{p}<0.01)$ downward trend in monthly injury rates between January 1997 and June 2000.

\section{Playground safety audits}

In 1998, 48 child care regulatory consultants completed a total of 294 playground safety audits. In 2000, certified playground safety inspectors examined 76 of the original 294 playgrounds. Inspectors rated each playground on 10 "playground safety concerns" having to do with disabled accessibility, fencing, and the developmental appropriateness of equipment on a three point rating scale where $0=$ poor, $1=$ fair, and $2=$ good. A similar three point scale was used for rating 18 specific "playground safety features" common to different types of equipment. These features include sharp points, protrusions, head entrapment risks, tripping hazards, fall zones, and surfacing features.

Direct comparisons of 1998 with 2000 playground safety ratings were made for the subset of 76 centers included in both audits. Figure 3 shows the change in average ratings between 1998 and 2000 for 10 playground concerns. For nine of these 10 features, average ratings in 2000 were equal to or better than those in 1998. Accessibility for the disabled showed the greatest improvement.

Figure 4 shows the change in average ratings between 1998 and 2000 for 18 playground features common to different types of playground equipment. Between 1998 and 2000, ratings improved for 12 of the 18 features evaluated. Four features showed statistically significant (paired samples $t$ test, $\mathrm{p}<0.05$ ) improvements: no sharp points, wood parts smooth and without splinters, surfacing meets requirements in consultant's manual, and fall zones meet requirements in 
consultant's manual. Three features showed no change in ratings, and there were no features for which ratings significantly dropped between 1998 and 2000.

\section{Center director survey}

Altogether 178 completed surveys were returned for a response rate of $61 \%$. Twelve of the questionnaire items were similar to or identical with items from the 1992 survey by Browning et al. ${ }^{13}$ Fourt of the 12 questionnaire items demonstrated improvements, whereas sixł items got worse. Overall there did not seem to be a trend in self reported indoor safety hazards between 1992 and 1999.

\section{DISCUSSION}

The analyses of medically attended child care injury in North Carolina regulated child care facilities documented a pattern of injury that has been reported elsewhere. In both homes and centers, most of the injuries occurred in the morning; the majority occurred to boys; bumping into or being hit by something was the most frequent cause of injury; cuts and scrapes were the most common injury type; and head and neck was the most common anatomical site injured. In centers the most common location of injury was the playground, but in homes it was the classroom.

Importantly, the researchers were able to document changes in injury rates over time, hoping to describe any trends that might be attributable to the new playground safety regulations announced in January, 1996, and implemented over a five year period. In fact, there was a significant decline in the annual rate of reported medically attended injury in regulated North Carolina child care centers, where over $90 \%$ of the reported injuries took place, from calendar year 1997 through calendar year 1999. In practical terms, there was a $22 \%$ decline in the annual, medically attended injury rates in centers, from one medically attended injury per year for every 120 children enrolled in 1997 to one medically attended injury per year for every 153 children enrolled in 1999. Although the absolute numbers are far smaller, medically attended injury reports for child care homes also declined, in this case by $31 \%$. By comparison, the Consumer Product Safety Commission's National Electronic Injury Surveillance System estimated that there were 32 187, 35 283, and 35610 injuries among children 1 month to 5 years of age in 1997, 1998, and 1999, respectively, seen in US emergency departments for injuries involving "monkey bars and climbing equipment", "other playground equipment", and "playground equipment not specified". ${ }^{14}$ When divided by the US $0-5$ population in those same years, ${ }^{15-17}$ the rates (per thousand), 1.389, 1.534, and 1.559, can be seen to have risen.

The playground safety inspections demonstrated improvements in nine of 10 playground safety concerns and 12 of 18 playground safety features. Although the baseline inspections were conducted by child care regulatory consultants and the follow up inspections by certified playground safety inspectors, our expectation that the certified playground safety inspectors would be more rigorous suggests that the improvements are more likely to be real. Still in need of attention on child care center playgrounds are undersurfacing and fall zones. On the other hand the child care center director surveys did not reveal any dramatic changes in indoor safety hazards. In the case of indoor hazards, directors reported problems in the areas of monthly testing of smoke detectors, availability of

†Smoke detector present; smoke detector tested at least monthly; Poison Control Center number posted; records of children's injuries kept.

$¥$ No choking foods served to under $5 \mathrm{~s}$; poisonous substances either not present or stored in secure areas; hot water $<120^{\circ} \mathrm{F}$ at faucet; 911 or other emergency number posted; first aid kit present; syrup of ipecac present.

\section{Key points}

- This is, to the best of our knowledge, the first study from the US to associate new regulation of playground safety hazards in out-of-home child care with a decline in the rate of medically attended injury occurring in child care.

- The decline was associated with a decrease in observed hazards on child care playgrounds.

- No such change was noted in indoor safety hazards in child care, where no new regulations were promulgated.

- The decline occurred between 1997 and 1999, at the same time as the Consumer Product Safety Commission estimated that emergency department visits for playground injury in the US among children 1 month to 5 years of age increased.

syrup of ipecac, and avoidance of food that potentially could cause choking. Combined, these two results reinforce the inference that the reduction in medically attended injury followed from the regulatory changes which addressed outdoor, but not indoor, safety hazards.

The principal finding of this study, that the annual rate of reported, medically attended injuries occurring in regulated child care facilities in North Carolina declined significantly between January 1997 and December 1999, is very encouraging. To our knowledge this is the first time such a decline in state-wide child care injury rates has been associated with improved regulation of playground safety in regular, out-ofhome child care in the US. As researchers though we are obliged to acknowledge the limitations of this finding. The association between the process of implementation of North Carolina's playground safety regulations between January 1996 and January 2001, does not prove that the regulations themselves caused the change. It is likely that other factors, directly or indirectly associated with the new regulations, may also have had an effect. For example, it is possible that heightened awareness of child safety among providers and teachers could have led to enhanced supervision of children on the playground. We cannot rule out the possibility that providers were simply reporting fewer injury incidents, or that fewer injuries were referred for medical attention. However, even if total injuries haven't declined, it would be hard to hide the more severe injuries which we studied, the injuries that required medical attention. The fact that the risk of such injury occurring in child care declined by $22 \%$ over three years appears to be a positive outcome.

\section{APPENDIX: DEFINITION OF ANNUAL INJURY RATE}

The annual injury rate was estimated by dividing the total number of injuries for the calendar year by the average monthly enrollment for that year:

Number of reports for year $\mathrm{Y} \div$ (January enrollment + February enrollment $+\ldots+$ December enrollment/12). The result was then multiplied by 100000.

\section{ACKNOWLEDGEMENTS}

The authors would like to thank Carol W Runyan, PhD, Director, Injury Prevention Research Center, University of North Carolina at Chapel Hill, for her helpful advice and comments, and Kathy Cruz, Ada Goldovsky, Fouad Hassaan, Meg Pickel, Hyung Min Kim, and Margi Bhatt, Graduate Research Assistants.

Supported by contract \#5197 from the Division of Child Development North Carolina Department of Health and Human Services, Raleigh, North Carolina.

The incident report form, safety audit form, and four page self administered questionnaire are available from the authors on request.

\section{Authors' affiliations}

J B Kotch, J M Hussey, Department of Maternal and Child Health School of Public Health, University of North Carolina at Chapel Hill 
A Carter, Division of Child Development, North Carolina Department of Health and Human Services

\section{REFERENCES}

1 Hofferth SL. Child care in the United States today. Future Child 1996:6:41-61

2 Capizzano J, Adams G, Sonenstein F. Child care arrangements for children under five: variation across states. New federalism. National survey of America's families. Series B, No B-7. Washington, DC: The Urban Institute, 2000 (March).

3 Brimhall DW, Reaney LM, West J. Participation of kindergarteners through third-graders in before- and after-school care. Statistics in brief. Washington, DC: US Department of Education, National Center for Education Statistics (NCES 1999-013), 1999.

4 Briss PA, Sacks JJ, Addiss DG, et al. A nationwide study of the risk of injury associated with day care center attendance. Pediatrics 1994:93:364-8

5 Cummings $\mathbf{P}$, Rivara FP, Boase J, et al. Injuries and their relation to potential hazards in child day care. Inj Prev 1996;2:105-8.

6 Landman PF, Landman GB. Accidental injuries in children in day-care centers. Am J Dis Child 1987;141:292-3.

7 Rivara FP, DiGuiseppi C, Thompson RS, et al. Risk of injury to children less than 5 years of age in day care versus home care settings. Pediatrics 1989:84:1011-16.

8 Sacks JJ, Smith JD, Kaplan KM, et al. The epidemiology of injuries in Atlanta day-care centers. JAMA 1989;262:1641-5.
9 Kotch JB, Dufort VM, Stewart $P$, et al. Injuries among children in home and out-of-home care. Inj Prev 1997:3:267-71.

10 Gunn WJ, Pinsky PF, Sacks JJ, et al. Injuries and poisonings in out-of-home child care and home care. Am J Dis Child $1991 \cdot 145 \cdot 779-81$.

11 Weiss HB, Mathers LJ, Forjuoh SN, et al. Child and adolescent emergency department visit databook. Pittsburgh, PA: Center for Violence and Injury Prevention, Allegheny University of the Health Sciences, 1997.

12 UNC Smart Start Evaluation Team. Effect of a Smart Start playground improvement grant on child care playground safety hazards. Chapel Hill, NC. Frank Porter Graham Child Development Institute, 1998

13 Browning KS, Runyan CW, Kotch JB. A statewide survey of hazards in child care centers. Inj Prev 1996;2:202-7.

14 US Consumer Product Safety Commission. National Electronic Injury Surveillance System (NEISS) On-line. Available from: http:// www.cpsc.gov/library/neiss.html (5/12/03; cited 5/13/03)

15 US Census Bureau. Statistical abstract of the United States: 1998. Section 1. Population. Table No 16. Resident population by age and sex: 1997. Available from: http://www.census.gov/prod/3/98pubs/ 98statab/sasec1.pdf (4 December 1998; cited 5/13/03).

16 US Census Bureau. Statistical abstract of the United States: 1999. Section 1. Population. Table No 16. Resident population by age and sex: 1998. Available from: http://www.census.gov/prod/99pubs/ 99statab/sec01.pdf (13 December 1999; cited 5/13/03)

17 US Census Bureau. Statistical abstract of the United States: 2000. Table No 13. Resident population by sex and age: 1999. Available from: http://www.census.gov/prod/2001 pubs/statab/sec01.pdf (cited 5/13/03).

\section{LACUNAE}

\section{Safety advice needed}

great deal can change over a generation when it comes to keeping babies safe. It is important for new grandparents to keep up to date, so if you have any tips for Injury Prevention editor Barry Pless and his wife, Ann, please send them to barry.pless@mcgill.ca as they became grandparents for the first time in April! Grandfather and grandmother are doing well.

\section{"Drunk on Life": Australian Boozie Awards}

n imitation of industry awards the Australian Drug Foundation gives TV awards in recognition of "excessive, inappropriate or unconscionable marketing of alcohol", called the "Boozie Awards". A very popular drama series The Secret Life of Us was nominated for seven Australian TV Awards (Logies) and won a "Boozie" on the basis that, on average, one in four of its scenes involves drinking. Males feature in $80 \%$ of alcohol scenes compared with $53 \%$ for females. No character in the series is a non-drinker. Geoff Munro, director of the foundation's Centre for Youth Drug Studies, says: "It is not an accurate portrayal of alcohol in young lives. Fifteen percent of young Australians aged 20 to 29 years do not drink and another 35\% only drink occasionally" (based on a report in the Sydney Morning Herald, May 2003; submitted by Ian Scott) 